\title{
Identifying the Type of a Contract to Transfer Health Services to Charities in Teaching Hospitals of Shahid Beheshti University of Medical Sciences in Tehran,
} Iran

\author{
Mahmud Nayeri ${ }^{1}$, Somayeh Hessam ${ }^{2 *}$, Amir Ashkan Nasiripour ${ }^{1}$, Katayoun Jahangiri ${ }^{3}$ \\ ${ }^{1}$ Department of Health Services Administration, Science and Research Branch, Islamic Azad University, Tehran, Iran \\ ${ }^{2}$ Department of Health Services Administration, South Tehran Branch, Islamic Azad University, Tehran, Iran \\ ${ }^{3}$ Safety Promotion and Injury Prevention Research Center, School of Public Health and Safety, Shahid Beheshti \\ University of Medical Sciences, Tehran, Iran
}

*Corresponding Author: Somayeh Hesam, Ph.D., Assistant Professor, Department of Health Services Administration, South Tehran Branch, Islamic Azad University, Tehran, Iran. Tel: +98-9335622512, Email: somayehh59@yahoo.com

Received July 4, 2020; Accepted October 7, 2020; Online Published October 19, 2020

\begin{abstract}
Background: One of the most important issues in the health system is to provide the necessary resources to present health services. To increase the role of charities and facilitate public participation in the treatment area and to develop hospital units, the cooperation between charity organizations and public hospitals must be highlighted.

Objectives: This study aimed at identifying the type of contract for the transfer of health services to charities in the teaching hospitals of Shahid Beheshti University of Medical Sciences in Tehran, Iran.

Methods: This study was conducted in hospitals of Shahid Beheshti University of Medical Sciences in 2019. The statistical population of the study consisted of 411 people, including managers, chiefs, and deputies, contracting experts, hospital social workers, managers and lawyers of the university, trustees, and managers, and charity experts. The research sample consisted of 330 people who were selected using a stratified random sampling method. SPSS version 18 and AMOS software were used to analyze the data.

Results: By identifying the selection criteria of a charity to operate in the hospital, identifying the contract model, identifying the share of capital and current costs, and selecting the type of department in the contract with path coefficients of $0.78,0.72,0.68$, 0.73 , and 0.73 , respectively, it can be ensured that the costs of an inpatient ward were supplied by the charity during the contract term.

Conclusion: The study showed that the partnership contract model is the most appropriate type of contract in the transfer of health services to charities.

Keywords: Charities, Contract, Hospitals, Teaching, Health Services
\end{abstract}

\section{Background}

One of the crucial issues in providing health services in each country's health system is to supply the necessary resources to provide these services. ${ }^{1}$ One of the biggest problems of health managers is financing. ${ }^{2,3}$ In Iran, the public health sector has failed quantitatively and qualitatively to meet the needs of patients, especially poor people. ${ }^{4,5}$ Voluntary motivation based on self-sacrifice and altruism towards private institutions and their higher efficiency and lower costs compared to the public sector to provide social and public services has led to paying increasing attention to communities and economic knowledge to promote productivity as well as scientific and practical development of this section. ${ }^{6,7}$ Non-governmental organizations play an essential role in creating and providing health facilities and services. ${ }^{89}$ It is clear that the public sector, whether it wants to or not, non-governmental organizations continue their work as a spontaneous government. Hence, having interaction between governmental and non-governmental sectors is effective in achieving developmental goals. There are obstacles to the achievement of goals of the non-governmental organizations, such as limited financial resources, an insufficient relationship between nongovernmental organizations and the government. Thus, the position of health charities in the Ministry of Health should be specified. ${ }^{2,4}$ Charitable organizations deal with the problems and needs of the target community as a specific plan. They provide the necessary financial

Copyright $\odot 2020$ The Author(s). This is an open-access article distributed under the terms of the Creative Commons Attribution License (http:// creativecommons.org/licenses/by/4.0), which permits unrestricted use, distribution, and reproduction in any medium, provided the original work is properly cited. 
resources to meet these needs through the public by creating or using financial platforms. ${ }^{10}$

Providing the necessary conditions for the establishment of a charity institution beside each public hospital to support that hospital is essential to increase the role of charities and facilitate the process of public participation in the field of treatment and welfare of patients and development of hospital units. ${ }^{11,12}$ Different organizations operate together in different models of cooperation. ${ }^{13,14}$ Selecting the most appropriate transfer method plays a significant role in success and failure. Thus, managers need to gain knowledge on transfer methods and identify the effective factors in selecting the appropriate method. ${ }^{15}$ In the health system transformation plan, an emphasis has been on organizing the participation of health charities, and an interaction model should be designed and implemented in the health sector between government and non-governmental organizations.

\section{Objectives}

Given the importance of public participation in health promotion and given that public assistance currently plays a significant role in improving public health services, especially at the level of university hospitals, it is necessary to increase the role of donors and facilitate the process of their participation in the field of treatment and welfare of patients and the development of hospital units to provide the necessary contexts for the establishment of a charity organization along with each of the government hospitals to support that hospital. This study aimed at identifying the type of contract for the transfer of health services to charities in the teaching hospitals of Shahid Beheshti University of Medical Sciences in Tehran, Iran.

\section{Methods}

The present study was a descriptive-analytical, crosssectional, and applied study, conducted in teaching hospitals of Shahid Beheshti University of Medical Sciences in Tehran, Iran in 2019. It was conducted in two phases. The first phase was a qualitative section which consisted of a library study and a literature review. Its data were collected from a series of references including databases, reference books, reports published by the World Health Organization (WHO), universities, research centers, lectures and articles presented at scientific conferences (published as books and journals), articles published in the last ten years, valid quarterlies and publications, documents and information banks such as Medline, PubMed, Elsevier and other sites related to the Ministry of Health and Medical Education and other authorities, including governmental and non-governmental organizations and theses available at the National Library, Shahid Beheshti University of Medical Sciences and Islamic Azad University (Science and Research Branch) in Tehran, Iran during 2006-2019. Making use of similarity and difference points, the initial research model was presented in five dimensions, including indicators for selecting a supportive organization with ten variables, determining the type of contract with four variables, sharing consumption and current costs with eight variables, sharing capital costs with five variables and selecting inpatient ward with seven variables. Then, a researcher-made questionnaire was designed according to the initial model and the tools used in studies conducted by WHO and Bottiglia and Health Services Assignment Guidelines. ${ }^{16-18}$

In the second phase of the research, in the quantitative section, the researcher-made questionnaire and a schematic outline of the suggested model with a description of the model dimensions were given to 20 experts to validate the researcher-made questionnaire. The experts included hospital managers, authorities of Shahid Beheshti University of Medical Sciences, and charity institutions in Tehran, Iran. All experts had PhD and MA degrees in the fields of health and management, contract affairs, and charity. Using the opinions of experts in these areas, important items within the scope of research were included, and other items were excluded in the researchermade questionnaire. The face and content validities of the questionnaire were confirmed in two phases. The first phase was performed using the Delphi method, and the second phase was performed by content analysis. The Cronbach's alpha coefficient was used to examine the reliability of each studied dimension, first separately and then together. Cronbach's alpha coefficient of the questionnaire was obtained at 0.932 . The Likert five-point scale was used to measure each item on the questionnaire $(1=$ very low, $2=$ low, $3=$ moderate, $4=$ high, and $5=$ very high) and based on the effect of variables on the way of cooperating based on the respondents.

The statistical population of the study included managers, chairman, deputies, and experts of contracts as well as hospital assistance experts, managers and legal experts of the university headquarters, the board of trustees of charities as well as managers and experts of charity centres. A stratified random method was used for sampling. The statistical sample size was estimated using Cochran's formula. The research sample was calculated to be 300 people (Table 1). To complete the number of samples, and due to the possibility of non-cooperation or elimination of -incompleted questionnaires, 330 questionnaires were distributed. Finally, 300 completed questionnaires were collected. Also, Bartlett and KMO tests were used to examine the adequacy of the sample for each variable in the model and the complete model. The inclusion criteria of the research were the organizational position of individuals and their employment in management departments, medical units, and charity institutions. To comply with ethical considerations, the objectives of the research were explained to the respondents, and they voluntarily participated in the research. They were ensured that the information in their questionnaire would remain confidential.

Demographic data were analyzed using descriptive statistical methods, and the Kolmogorov-Smirnov test was 
Table 1. Sample Research Separately in Each Category

\begin{tabular}{|c|c|c|c|c|c|}
\hline & Target Population & Quantity of Target Population & The Coefficient of Division & Sampl & esearch \\
\hline 1 & The managers, chairman, and deputies of the hospital & 138 & 0.34 & 90 & 101 \\
\hline 2 & Hospital contracts experts & 91 & 0.22 & 60 & 66 \\
\hline 3 & Managers and legal experts of the university headquarters & 30 & 0.07 & 20 & 22 \\
\hline 4 & Board of trustees of charities & 24 & 0.06 & 16 & 18 \\
\hline 5 & Experts of charity centers & 128 & 0.31 & 84 & 93 \\
\hline Total & & 411 & 1 & 270 & 300 \\
\hline
\end{tabular}

used to check the normality of data, and Levene's test was used to check the homogeneity of the data. To identify the effective factors, three indices of eigenvalue, the ratio of variance explained by each factor, and the rotated screen diagram and varimax rotation were used for exploratory factor analysis. Then, to confirm the factors extracted from the questionnaire in the factor analysis stage, the confirmatory factor analysis model was used in SPSS version 18 and AMOS software.

\section{Results}

In the present study, out of 300 respondents, 144 (48\%) were female, and 156 (52\%) were male. The mean employment history of respondents was 13 years. The KMO test was used to measure the adequacy of the sample for each variable in the model and the complete model, the results of which are shown in Table 2. It means that the amount of intra-data variance explained by the factors is acceptable. The null hypothesis of the Bartlett test was rejected at significance $<0.001$. In exploratory factor analysis, using the matrix of rotated factors with varimax rotation, it was shown that each factor includes which variables (Table 2). According to the questionnaire and the titles considered for these dimensions, the first factor is the indicator of selecting supportive organizations, the second factor is determining the contract model, the third factor is the share of consumption and current costs, and the fourth factor is determining capital costs, and the fifth factor is the indicator of selecting inpatient ward (Figure 1).

This model was estimated after stipulating the condition of proving the parameters of the University of Medical Sciences linked with financial resources of supporting organizations to determine the share of capital. The multivariate normality (Mardia's coefficient) was equal to 19.02, which indicates the non-normality of this model. Therefore, the bootstrap method should be used to examine the coefficients. The fit indices are described as follows (Table 3 ).

The standardized path coefficients and bootstrap of the structural research model with a $95 \%$ confidence interval and bootstrap significance are shown in Table 4 and Table 5.

\section{Discussion}

The present study showed that in the first dimension of indicators of selecting a supportive organization with the Standard Estimate of 0.825 , the most effective variable is "having a standard accounting system" with a path
Table 2. Matrix of Rotated Factors With Varimax Rotation

\begin{tabular}{|c|c|c|c|c|c|}
\hline \multirow{2}{*}{$\begin{array}{l}\text { Question } \\
\text { number }\end{array}$} & \multicolumn{5}{|c|}{ Final factors } \\
\hline & 1 & 2 & 3 & 4 & 5 \\
\hline \multirow[t]{36}{*}{ Variance } & 52.5 & 73.12 & 89.25 & 91.45 & 100 \\
\hline & 0.75 & & & & \\
\hline & 0.69 & & & & \\
\hline & 0.76 & & & & \\
\hline & 0.72 & & & & \\
\hline & 0.70 & & & & \\
\hline & 0.70 & & & & \\
\hline & 0.66 & & & & \\
\hline & 0.70 & & & & \\
\hline & 0.79 & & & & \\
\hline & 0.77 & & & & \\
\hline & & & & & 0.62 \\
\hline & & & & & 0.64 \\
\hline & & & & & 0.72 \\
\hline & & & & & 0.75 \\
\hline & & 0.61 & & & \\
\hline & & 0.66 & & & \\
\hline & & 0.69 & & & \\
\hline & & 0.65 & & & \\
\hline & & 0.68 & & & \\
\hline & & 0.67 & & & \\
\hline & & 0.63 & & & \\
\hline & & 0.63 & & & \\
\hline & & 0.71 & & & \\
\hline & & & & 0.69 & \\
\hline & & & & 0.75 & \\
\hline & & & & 0.72 & \\
\hline & & & & 0.71 & \\
\hline & & & & 0.76 & \\
\hline & & & 0.72 & & \\
\hline & & & 0.68 & & \\
\hline & & & 0.67 & & \\
\hline & & & 0.68 & & \\
\hline & & & 0.74 & & \\
\hline & & & 0.62 & & \\
\hline & & & 0.62 & & \\
\hline \multirow{2}{*}{ KMO Test } & \multicolumn{5}{|c|}{ Bartlett Test } \\
\hline & Chi- & Statistic & & df & $P$ Value \\
\hline 0.84 & & 15 & & 703 & $0.001>$ \\
\hline
\end{tabular}




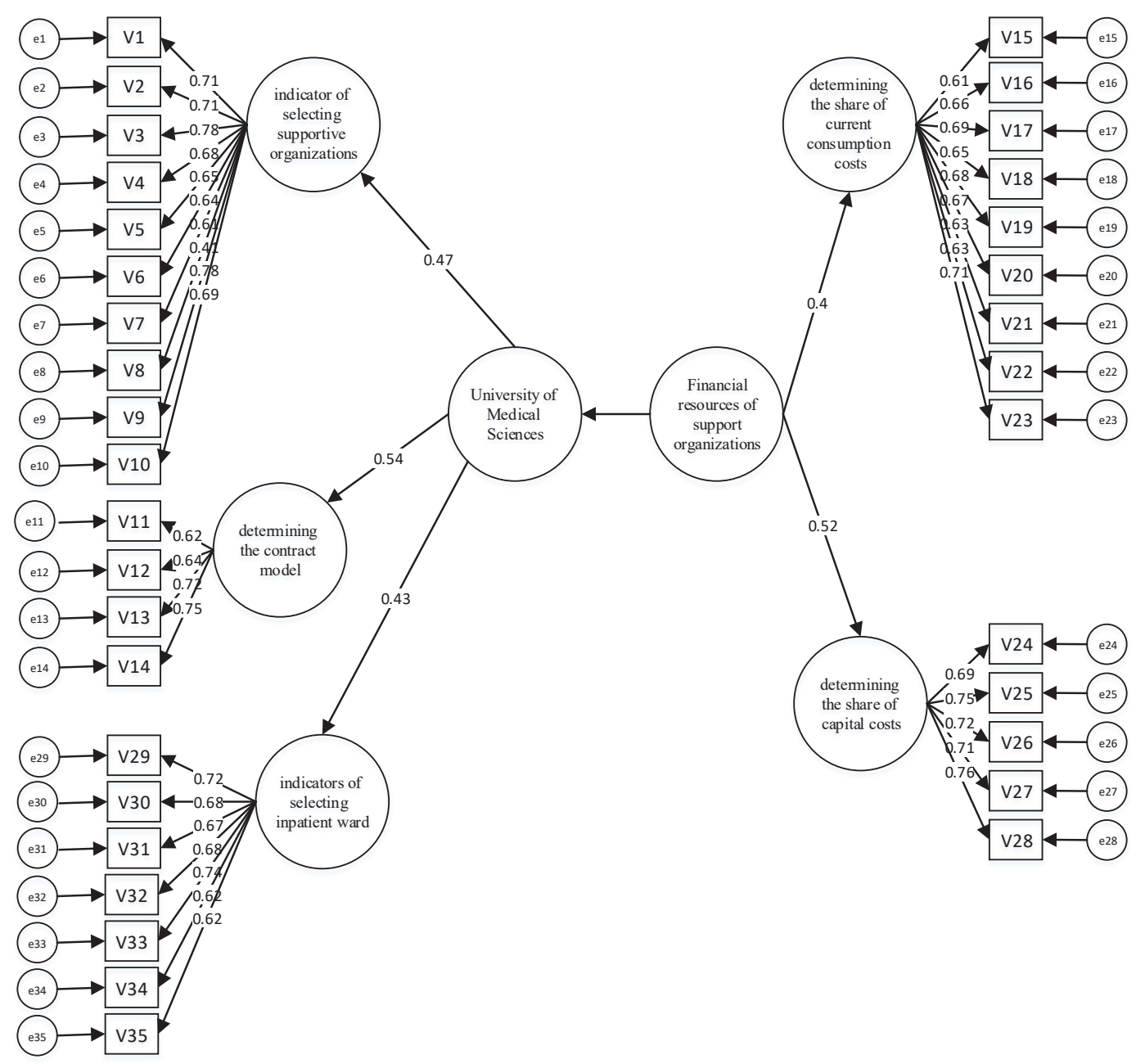

Figure 1. Confirmatory Factor Analysis (Model) and Standardized Path Coefficients.

coefficient of 0.78 , and in contrast, the least effective variable of this dimension is "resources of agency offices and branches that should be spent at agency site" with a path coefficient of 0.41 , ensuring the operation of associations, foundations, and charity organizations in accordance with the set plans and policies and correcting possible deviations requires monitoring and control. The lack of an integrated and systematic monitoring system has led to the possibility of some financial abuses and violations through charity institutions. Charities institutions should have a standard accounting system with financial transparency in the areas of the level of

Table 3. Structural Model Fit Indices After Applying Correction Indices

\begin{tabular}{lcc}
\hline Index & Index Value & Acceptable Value \\
\hline CMIN/DF & 1.43 & $<3$ \\
GFI & 0.86 & $>0.8$ \\
AGFI & 0.84 & $>0.8$ \\
CFI & 0.92 & $>0.9$ \\
IFI & 0.92 & $>0.9$ \\
TLI & 0.91 & $>0.9$ \\
RMSEA & 0.04 & $<0.05$ or $<0.08$ \\
\hline
\end{tabular}

income, areas to spend the income, the number of clients, and the type of services provided. ${ }^{19}$ Article 2 of the circular of regulations for collecting public donations by the charity and non-profit organizations also emphasizes the formation of a working group to organize and monitor the activities of charity organizations by provincial and city supervisory boards. ${ }^{17}$ Also, Article 4 of the guidelines, in terms of establishment, activities of branches and agency offices of non-profit organizations (regulations for the establishment of charity organizations in medical centers, 2018) emphasizes the existence of an independent auditor to independently evaluate the financial and executive performance of charity institutions with branches and agencies. ${ }^{19}$ The charity institution supporting a public hospital is a completely independent charity institution and even has an independent bank account. According to a Global Tolerance Survey, approximately $75 \%$ of the world population wants transparency in governance, business, and non-profit organizations. ${ }^{20}$

Public trust is considered as one of the vital factors for the development and attraction of donors to charities. In this regard, other points that worth mentioning include forming an annual general assembly in the supportive organization, assigning a specific bank account to deposit 
A Cooperative Management Model Between Charities and Hospitals

Table 4. Standardized Path Coefficients and Bootstrap Structural Research Model

\begin{tabular}{|c|c|c|c|c|c|c|}
\hline \multirow{2}{*}{ Parameter } & \multirow{2}{*}{ Standardized Estimate } & \multicolumn{5}{|c|}{ Bootstrap } \\
\hline & & Standard Estimate & Estimate & Upper Bound & Lower Bound & $P$ Value \\
\hline $\begin{array}{l}\text { Indicator of selecting supportive } \\
\text { organizations }\end{array}$ & Universities of Medical Sciences & 0.825 & 1.158 & 2.569 & 0.308 & 0.032 \\
\hline Determining the contract model & Universities of Medical Sciences & 1.177 & 1.677 & 2.967 & 0.669 & 0.041 \\
\hline Indicators of selecting inpatient ward & Universities of Medical Sciences & 0.824 & 1.313 & 3.648 & 0.192 & 0.021 \\
\hline $\begin{array}{l}\text { Determining the share of current } \\
\text { consumption costs }\end{array}$ & Universities of Medical Sciences & 0.530 & 0.549 & 1.020 & 0.146 & 0.010 \\
\hline Determining the share of capital costs & Universities of Medical Sciences & 1.000 & 1.000 & 1.000 & 1.000 & - \\
\hline
\end{tabular}

and withdraw from the account with the name of the supportive organization, having a certificate of good service records, specified capital at the disposal of the supportive organization (movable and immovable) and expenditure of all resources resulting from agency offices and branches at agency site. ${ }^{21}$

Pakdaman et al stated that associations and charities are no exception in this regard. To ensure that they operate according to established plans and policies and to correct

Table 5. Standardized Path Coefficients

\begin{tabular}{|c|c|c|}
\hline Question & Hidden Variable & $\begin{array}{c}\text { Path } \\
\text { Coefficient }\end{array}$ \\
\hline S1 & Indicator of selecting supportive organizations & 0.71 \\
\hline S2 & Indicator of selecting supportive organizations & 0.71 \\
\hline S3 & Indicator of selecting supportive organizations & 0.78 \\
\hline S4 & Indicator of selecting supportive organizations & 0.68 \\
\hline S5 & Indicator of selecting supportive organizations & 0.65 \\
\hline S6 & Indicator of selecting supportive organizations & 0.64 \\
\hline S7 & Indicator of selecting supportive organizations & 0.61 \\
\hline S8 & Indicator of selecting supportive organizations & 0.41 \\
\hline S9 & Indicator of selecting supportive organizations & 0.78 \\
\hline S10 & Indicator of selecting supportive organizations & 0.69 \\
\hline S11 & Determining the contract model & 0.62 \\
\hline S12 & Determining the contract model & 0.64 \\
\hline S13 & Determining the contract model & 0.72 \\
\hline S14 & Determining the contract model & 0.75 \\
\hline S15 & Determining the share of current consumption costs & 0.61 \\
\hline S16 & Determining the share of current consumption costs & 0.66 \\
\hline S17 & Determining the share of current consumption costs & 0.69 \\
\hline S18 & Determining the share of current consumption costs & 0.65 \\
\hline S19 & Determining the share of current consumption costs & 0.68 \\
\hline S20 & Determining the share of current consumption costs & 0.67 \\
\hline S21 & Determining the share of current consumption costs & 0.63 \\
\hline S22 & Determining the share of current consumption costs & 0.63 \\
\hline S23 & Determining the share of current consumption costs & 0.71 \\
\hline S24 & Determining the share of capital costs & 0.69 \\
\hline S25 & Determining the share of capital costs & 0.75 \\
\hline S26 & Determining the share of capital costs & 0.72 \\
\hline S27 & Determining the share of capital costs & 0.71 \\
\hline S28 & Determining the share of capital costs & 0.76 \\
\hline S29 & Indicators of selecting inpatient ward & 0.72 \\
\hline S30 & Indicators of selecting inpatient ward & 0.68 \\
\hline S31 & Indicators of selecting inpatient ward & 0.67 \\
\hline S32 & Indicators of selecting inpatient ward & 0.68 \\
\hline S33 & Indicators of selecting inpatient ward & 0.74 \\
\hline S34 & Indicators of selecting inpatient ward & 0.62 \\
\hline S35 & Indicators of selecting inpatient ward & 0.62 \\
\hline
\end{tabular}

possible deviations requires monitoring and control. ${ }^{22}$

In the second dimension of determining the type of contract with the Standard Estimate of 1.177, the most effective variable was "participation contract with the nongovernmental sector" with a path coefficient of 0.72 , and the least effective variable of this dimension was "contract of purchasing services from the non-governmental sector" with a path coefficient of 0.41 . Based on the Health Services Transfer Guidelines, there are three types of contract models:

(1) Contract for purchasing services from the nongovernmental sector (using the capacities of the nongovernmental sector by paying per capita cost of providing services that public institution is responsible for them according to existing laws and regulations. (2) Participation contract with the non-governmental sector (providing units belonging to governmental institution in the form of participation or leasing to non-governmental legal and real persons. (3) Contract for transfer of management to the non-governmental sector (transfer of administration of affairs under the responsibility of a public institution to eligible or legal persons specified in law while retaining government ownership). Due to their inherent capabilities, non-governmental organizations can be very effective if the organization is managed scientifically, and their guidelines are implemented correctly. ${ }^{21}$

It seems that the government should make more efforts to attract more participation in this sector. Based on the studies conducted in this regard, governments alone cannot afford to finance because they have limited resources to provide services, and there is inappropriate management, inefficiency, time and cost, and poor quality services in public sector performance. Hence, the participation of the private and public sectors is expected to yield better results. The quality of services provided by governments is not desirable, and private sector services are too expensive and do not meet social benefits. Hence, it is predicted that public-private participation models can be very helpful although in England, the methods of the rental contract, service purchase, and outsourcing are common. Bull and et al highlighted the factors determining the type of contract and private sector participation in US infrastructure projects after describing the types of participation contracts and their advantages and disadvantages on selection had been emphasized as the best type of contract. ${ }^{23}$ 
In the third dimension of consumption and current costs, "share of capital costs of purchasing equipment" was the most effective variable with a path coefficient of 0.68 and the least effective variable of this dimension was "the share of current costs of legal deductions, tax debts and value-added" with a path coefficient of 0.46 . The share of ward costs, including administrative necessities, hoteling consumption costs, current costs of paying staff wages and fees, patient assistance costs, current costs of energy carriers of the ward, current costs of equipment maintenance, current costs of legal deductions, tax debts and valueadded and other financial obligations, current costs related to advertising, collecting financial aids and the costs of purchasing medical supplies are under the responsibility of the charity institution which can be added to the contract. The collected financial resources are allocated to developing the physical space, providing equipment and consumables, paying the wages of staff of charity medical centers, and paying for patients' health services. The implementation of the health system transformation plan has had a positive impact on the activities of NGOs and has overshadowed their field of activity, leading to the development of health services, financing and allocation of resources, providing medical equipment as well as prevention and promotion of health by NGOs. ${ }^{24}$

Maher et al. stated that the major part of the costs of health centers is consumption and current costs. Health centers usually have problems in this area. Payroll staff official supplies, consumables, equipment maintenance, and repair costs have created many problems for managers of public hospitals especialy. ${ }^{25}$

In the fourth dimension of the share of capital costs with the Standard Estimate of 1, the most effective variable was "obtaining the necessary license and purchasing capital equipment" with a path coefficient of 0.73 and the least effective variable of this dimension was "physical space development" with a path coefficient of 0.61 . Based on the regulations of Article 10 of the law on the completion of semi-finished projects with the participation of donors, ${ }^{26}$ donors can cooperate with Iran's medical universities in the construction and development of physical space of health care organizations.

Executive organizations are allowed to complete their projects based on a contract with donors and using their participation. ${ }^{17}$ Mayo Clinic also operates as a charity training center to supply the capital costs, develop longterm financial models, including cash flows and capital costs, as well as monitoring annual operating budgets within a specific structure. Also, Mayo Clinic assesses capital cost in the program designated for affiliates. The method is used in Mayo Clinic, as a charity, to forecast annual consumption and current and capital costs, consistent with the present study. ${ }^{27}$

In the Fifth dimension of selecting inpatient ward, with a Standard Estimate of 0.842 , the most effective variable was "selection of radiotherapy and oncology wards" with a path coefficient of 0.73 , and the least effective variable of this dimension was "selecting other inpatient wards" with a path coefficient of 0.38 .

Dan and et al. conducted a survey and cross-sectional research on AIDS patients to analyze and explore behaviour and attitudes of the Canadian population towards charity donations in the type of diseases. They found that despite the general humanitarian orientation, few people were interested in charitable donations for AIDS, that is, the right selection is effective in attracting support. ${ }^{28}$ However, based on the results of the present study, it can be stated that with the joint transfer of a hospital ward and with the preferred transfer of priority to the radiotherapy and oncology, dialysis, and pediatric wards, in which both charities and people are willing to participate, and the use of the credit of a public hospital, a charity institution can attract the people aids and donations and managers can gain benefit from a sustainable financial support. ${ }^{29}$

\section{Conclusion}

The present study also criticizes the decision of the Ministry of Health, which insists on the establishment of a charity institution by the hospital, and points out that the hospital does not perform the correct process of attracting and retaining donors, given that the organizational behaviour of government employees shows that busy employees do not have the opportunity to work appropriately and professionally. Finally, the following recommendations are presented for future research.

- Designing a clear, accurate, and practical model to sign a contract in the area of health

- Designing an educational model for managers of organizations to interact with charities

- Identifying and examining beneficial communication variables between the public and private sectors

- Investigating the way of distributing and allocating donors' resources in Iran's health system and providing a model for the equitable allocation of health system donors' resources

- Providing a model for retaining donors in the health syste

- Identifying the factors affecting the structural development of a successful charity institution

- Supporting mechanisms that strengthen the relationship and participation between the private and public sectors

- Providing a model for establishing non-governmental organizations that facilitate charity affairs

\section{Authors' Contributions}

All authors contributed equally to this article.

\section{Conflict of Interest Disclosures}

The authors declare that they have no conflicts of interest.

\section{Ethical Approval}

This study was approved by Science and Research Branch, Islamic Azad University Ethics Committee. 


\section{Research Highlights}

\section{What Is Already Known?}

It has been reported that health centers should use the capacity of financial charity organizations to provide the funds. Also, there has been an emphasis on maintaining sponsors.

\section{What This Study Adds?}

This study showed that with the joint transfer of a hospital ward where charities are willing to participate and people are more proactive in helping, it is possible to use the credit of a public hospital to attract public donations by the charity. At the same time, managers benefit from stable support to provide financial resources.

\section{Acknowledgments}

The authors of this study thereby appreciate all staff and managers of the teaching hospitals of Shahid Beheshti University of Medical Sciences and Behnam Dahesh Pour charity organization in Tehran, Iran for their support and cooperation in this research.

\section{References}

1. Doshmangir L, Azimzadeh S. A comparative study of health financing frameworks. J Health Syst Res. 2018;14(2):142-152. doi:10.22122/jhsr.v14i2.3273. [Persian].

2. Toghyani M, Derakhshan M, Nasroallahi K. A theoretical model for preserving the endowment and charities in the third sector of the economy with asymmetric information. Islam Econ Stud. 2014;7(1):153-182. [Persian].

3. Jeong HS. Health care reform and change in public-private mix of financing: a Korean case. Health Policy. 2005;74(2):133145.

4. Nasiripour A, Maleki M, Gohari M, Aghababa S, Vahedi M. The role of governance in social marketing of charities: focus on health care system. Health Information Management. 2014;11(1):1-3. [Persian].

5. Shafiei Nikabadi M, Razaviyan SB. Identification and ranking of effective indicators on the loyalty of the charities in Iranian charities using Fuzzy Delphi and Structural Interpretative Equation. Quarterly Journal of Socio-Cultural Development Studies. 2018;6(3):59-79. [Persian].

6. Nekoei-Moghadam M, Amiryousefi S, Ghorbani Bahabadi Z, Amiresmaili M. Role of charities in the health system: a qualitative study. Journal of Qualitative Research in Health Sciences. 2013;2(1):1-10. [Persian].

7. Xue Q, Niu Y. Governance and transparency of the Chinese charity foundations. Asian Review of Accounting. 2019;27(2):307-327. doi:10.1108/ARA-03-2018-0057.

8. Mohammadi A, Askarzadeh E, Pourahmadi E, Hoseinolho seini N, Vafaee Nagar A. Study of the performance of NGOs in financing the cost of treatment for patients in Mashhad University of Medical Sciences. Medical Journal of Mashhad University of Medical Sciences. 2019;62(1):1355-1362. doi:10.22038/mjms.2019.13837. [Persian].

9. Bordignon $M$, Grembi V, Piazza S. Who do you blame in local finance? an analysis of municipal financing in Italy. Eur J Polit Econ. 2017;49:146-163. doi:10.1016/j.ejpoleco.2017.02.003.

10. Jesmani M, Rashid Lamir A, Gharekhani H, Dehghan Ghahfarokhi A. Identifying and prioritizing economic and managerial barriers for championship sport in Zanjan province. Sport Physiology \& Management Investigations. 2019;10(4):101-110. [Persian].

11. Katoziyan $\mathrm{N}$. The evolution of the endowment institution and its future prospects; comparative-historical study. Journal of Philosophy \& Theology. 2017;21(5):63-79. [Persian].

12. Vatankhah S, Maleki M, Tofighi S, Barati O, Rafiei S. The study of management contract conditions in healthcare organizations of selected countries. Health Information Management. 2012;9(3):424-431. [Persian].

13. Mosakhani M, Maniyan A, Ehghaghi E. A model collaborative maturity assessment in inter-organizational networks case study: Shabab network. Management Research in Iran. 2014;18(3):157-180. [Persian].

14. Bromideh AA, Rezaei A, Bromand-Rad H, Aarabi N. The impact of health system reform plan on NGOs's activities in health sector. Journal of Health Based Research. 2017;2(4):355-368. [Persian].

15. Aghababa S, Maleki M, Gohari M. Narrative review of studies on charity in health care, Iran. Hakim Health Systems Research Journal. 2015;17(4): 329-336. [Persian].

16. Bottiglia R. Competitive frontiers in P2P lending crowdfunding. In: Crowdfunding for SMEs. London: Palgrave Macmillan; 2016. p. 61-92. doi:10.1057/978-1-137-56021-6_4.

17. Cordery CJ, Sim D, van Zijl T. Differentiated regulation: The case of charities. Accounting \& Finance. 2017;57(1):131-164.

18. World Health Organization (WHO). The World Health Report 2000: Health Systems: Improving Performance. Geneva, Switzerland: WHO; 2000. p. 25.

19. Nosrati M, Sadeghi H, Abdoli G, Agheli-Kohnehshahri L. Applying public-private partnership investment model in health: assessment of hospital readiness in Iran. Journal of Management and Medical Informatics School. 2013;1(2):128137. [Persian].

20. Hurley R. The BMJ charity appeal Christmas 2017: help Médecins Sans Frontières help child refugees worldwide. BMJ. 2018;360:k349. doi:10.1136/bmj.k349.

21. Mosadeghrad A, Tajvar M, Ehteshami F. Donors' participation in financing health system of Iran. Hakim Health Systems Research Journal. 2019;22(1):26-42. [Persian].

22. Pakdaman $M$, Sari $M$, Montazeralfaraj $R$, Fallahzadeh $H$. Management pattern of health benefactors' collaboration in Medical Sciences Universities of Iran. Journal of Community Health Research. 2019;8(3):164-176. [Persian].

23. Bull D, Bagwell S, Nicholls J, Sheil F. Supporting Good Health: The Role of the Chritty Sector. London, UK: New Philanthropy Capital; 2014. p. 129-149.

24. Masoodipoor S, Bagheri Nasrabadi M. The prioritizing the key issues in the regulation of the relationship between the public sector and NGOs in the field of charities. Public Policy. 2018;4(3):141-158. [Persian].

25. Maher A. Measuring health sector performance in national development plans. Social Welfare Quarterly. 2003;2(8):121 152. [Persian].

26. Aghamohamadi S, Jahangiri K, Hajinabi K, Masoudi Asl I, Dehnavieh R. Foresight for inpatient beds in hospitals of Iran: vision 2035. Journal of Health Administration. 2018;21(71):2336. [Persian].

27. Helmers RA, Gabrielson SR, Harper MM. Developing a new governance structure: the Mayo Clinic experience. Physician Leadersh J. 2016;3(3):40-46.

28. Jessica L. SchleiferBA. Charity Care, Comunity Benefits By Hospital Type In Texas [dissertation]. Dallas: The University of Texas School of Public Health; December; 2010.

29. Nasiripour AA, Tofighi SH, Farhadi FA. Designing an administrative model for Iranian charity hospitals. Iran Journal of Nursing. 2007;20(50):71-81. 